\title{
蠕動運動型工業用内視鏡ロボット
}

\section{An In-pipe Mobile Robot for Use as an Industrial Endoscope Based on an Earthworm's Peristaltic Crawling}

\author{
○学 堀井 翔太 (中央大) 学 青木 孝平 (中央人) \\ 正 中村 太郎 (中央大)
}
Shota HORII, Chuo University, s_horii@bio.mech.chuo-u.ac.jp
Kohei AOKI, Chuo University
Taro NAKAMURA, Chuo University

\begin{abstract}
Recently, the number of pipe accidents has been increasing. Because most of these were caused by corrosions or deteriorations, in-pipe inspections have been performed with fiber scopes to prevent such problems; however, such pipes cannot inspect in pipes over $14[\mathrm{~m}]$ long or in complex pipes. Therefore, in-pipe inspection robots are required for such uses. In this paper, we propose the development of the robot that mimics the peristaltic crawling of earthworms as a locomotion mechanism. In addition, we performed two experiments in a $27[\mathrm{~mm}]$ diameter acrylic pipe and a $28[\mathrm{~mm}]$ diameter aluminum pipe to examine 1) the locomotion speed of the robot and 2) the relationship between propulsive force and motion patterns.
\end{abstract}

Key Words: Robot, Earthworm, Peristaltic Crawling, In-pipe

\section{1. 緒言}

急速な技術革新による機械や工場設備のハイテク化および 複雑化が進む現代社会において，不具合，ひいては異常運行 へと慗がる連鎖を断ち, 重大な事故を未然に防ぐ信頼性の高 いメンテナンスは, 社会にとって最も重要な課題のひとつと なっている，なかでもライフライン等の役割を担っている配 管のメンテナンスは, 配管の破裂や腐食による事故を防ぐ上 で必要不可欠である。

特に, 現在ガス管などの管の内部の検査に, メンテナンス 機器のひとつである工染用内視鏡が多く使われており，人の 目の届かない简所を工紧用内視鏡で観察し亀裂や腐食を確認 している，その作業方法としては工栄用内視鏡を于元から配 管内に押し込んで行く.また，曲管を通過寸る際は内視鏡内部 に通したワイヤーを引っ张ることで内視鏡先端の屈曲を採作 して通過している，既你の工栄用内視鏡には人り組んだ配管 内の検查や, 長さが $14[\mathrm{~m}]$ 程度を超える配管では使用できない 火点がある。これは，前述した状態になると工篓用内視鏡が 管内でたわみ，後ろからの押し込むノが前に伝わらなくなる ことが原因である。この様な状態になると押し込む力は工策 用内視鏿のたわみをより大きくさせる方向に作用してしまう. また，ワイヤーによる屈曲の㨐作もワイヤーと内视鏿内部之 の摩擦力が大きくなるので困難になってしまう.

これらの問題は内視鑜に自走機能を搭載することで解決で きると考えた。なお，先行研究として繊毛振動型 1 や蛇型 2 ロボットの工策用内視鏿が研究されているが, 後進出来ない, ロボットの幅に比心問の幅が必要，などの問題がある. 加え て，上記のような工栄用内視鏡の問題を解決するには至って いない.

そこで本研究ではミミズの蝡動運動に着月した螦動運動型 ロボットを工栄用内視鏿に応用することを考えた。

\section{2. ミミズの概要}

ミミズの体は約 150 の同じ楧造の体節から成り, その一つ 一つの体節を順に伸縮させることで螦動運動を行っている. 図１に蝡動運動によりミミズが前進する様子をホホす. 前進寸 る際，ミミズはまず頭部の体節を収縮させ，順に後方の体節
へとこの収縮を伝播する。この体節の収縮で地面との摩擦を 発生させ，摩擦を頼りにして前進する。

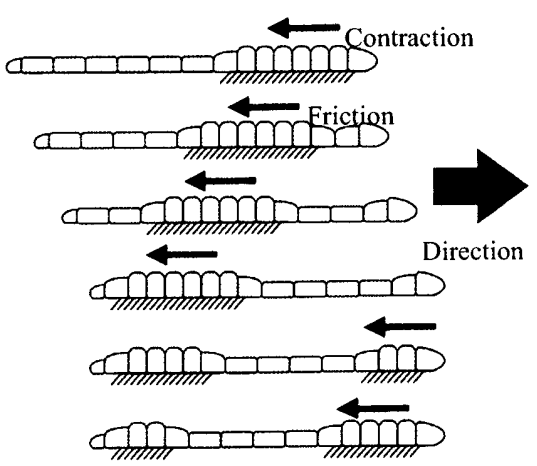

Fig. 1 Locomotion pattern of an earthworm

\section{3. 蠕動運動型ロボット}

\section{1 ロボットの概要}

図 2 に開発した蝡動運動型ロボットをボす。ロボットはミ ミズの複雑な檴造を単純化し，ミミズの体節一つをロボット の 1 ユニットと先站てて設計してある. ユニット一つ一つが ミミズの体節同様に伸縮運動を行うことができる。図 2 には 大きさの比較のためにタバコを獚に置いてある.ミミズ同棫 に管内走行ロボットもユニットを順序よく伸縮させることに より縦波後進波を発生させ，螦動運動を行う。径の小さい管 で走行ができるようにマイクロモータ(Naniki SBL07-12)を使 用した。

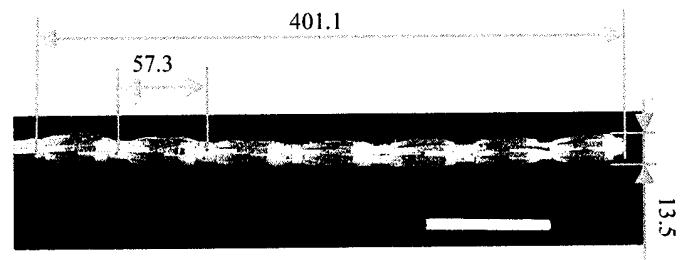

Fig. 2 The developed peristaltic crawling robot 


\section{2 ユニットの概要}

設計したユニットの概要図を図 3 に，その仕様を表 1 にそ

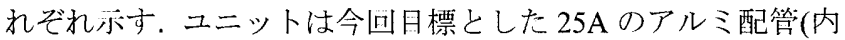
径 28. 0〜28.4[mm])に人る大きさにするためにマイクロモー 夕を使用し，ネジを使って動力を伝達する構造とした。ユニ ットの最大外柊は $25 \mathrm{~A}$ のアルミ配管(内怿 $28.0 \sim 28.4[\mathrm{~mm}]$ ) 内を走行することを月的としているためにべルトの変形分も 考虑し，余裕を持たせて $37.4[\mathrm{~mm}]$ 確保してある.

(a) Extension

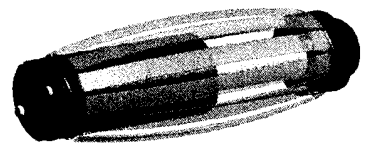

(b) Contraction

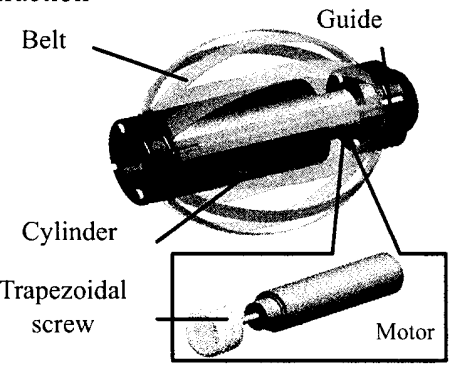

Fig. 3 Schematic view of a unit

Table. 1 Specification of a unit

\begin{tabular}{|c|c|c|}
\hline \multicolumn{2}{|c|}{ Weight $[\mathrm{g}]$} & 13.8 \\
\hline $\begin{array}{c}\text { Length } \\
{[\mathrm{mm}]}\end{array}$ & Extension & 57.3 \\
\cline { 2 - 3 } & Contraction & 44.3 \\
\hline $\begin{array}{c}\text { Width } \\
{[\mathrm{mm}]}\end{array}$ & Extension & 13.5 \\
\cline { 2 - 3 } & Contraction & 37.4 \\
\hline
\end{tabular}

\section{3 ユニットの伸張カ}

ギヤヘッドを取り付けモータのトルクを胡測した。その絬 果モータのトルクは最大で $0.48[\mathrm{~N}]$ であった。このトルクに基 づきにネジの推ノを求める，推ノ $Q$ と回転方响のノPがつり 合っていると仮定し，ネジの斜面を 1 ピッチ分展開した闵を 図 4 に亦寺。
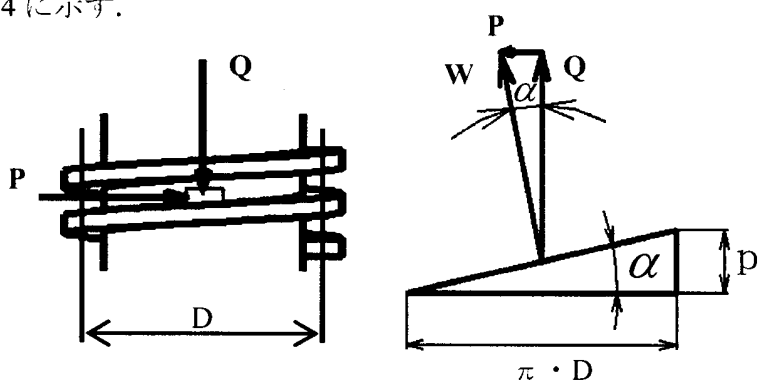

D : Effective diameter, $\quad \mathrm{p}$ : Pitch, $\alpha$ : Lead angle

$\mathrm{Q}$ : Thrust force, $\mathrm{P}$ : Direction force

Fig. 4 Configuration of the screw in a unit
このノの関係に摩擦角 $\theta$ を考慮すると， $P$ と $Q$ の関係は,

$$
Q=P / \tan (\alpha+\theta)
$$

となる(3).ここで $P$ をトルク $T$ で表すと，

$$
P=2 T / D
$$

さらに使用した台形ネジの角度を $\beta$ とすると摩擦角を考慮し たネジの推ノ $Q_{l}{ }^{\prime}$ は

$$
Q_{1}{ }^{\prime}=\frac{2 T}{D \tan \left\{\alpha+\arctan \left(\frac{\mu}{\cos \beta}\right)\right\}}
$$

と承まる。ここで，それぞれのパラメータに值を代人し計算 を行ったところ $Q_{1}{ }^{\prime}=5.03[\mathrm{~N}]$ となった. 実際に完成したユニッ トのノを測定したところ伸張力は $44.2[\mathrm{~N}]$ と理論值と近い値と った。このことからユニットの伸張力はモータトルクからケ 測できる。

\section{4. ロボットの走行実験}

\section{1 運動パターン}

ロボットの運動パターンとしては，図 5 に示すように4-1-1 型など様々なパターンがある。ここで波長とは伸張ユニット 数，送り汇波の伝播ユニット数である.

ロボットが蝡動運動をするためには波長を $l$, 送りを $n$, 波数 を $s$, 総ユニット数を $N$ とした時に, 以トの式を満たさなけれ ばならない.

$$
\begin{gathered}
(l+n) \times s<N \\
N-l>s
\end{gathered}
$$

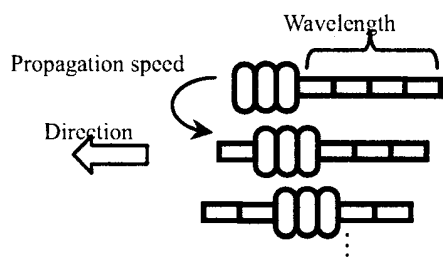

Fig. 4 Motion pattern 4-1-1

また、これら動作を、動作の中のユニットを考え, 運動パ夕 ーンをより滑らかに慗ぐことで速度の向上を図った中問動作 を提案した。図 5 に中問動作を考慮した運動パターンを小寸。 ロボットの動作を $m$ 個に分割するためには，以トの式(6)も満 たさなければならない。 また，送り $n$ は 1 となる。

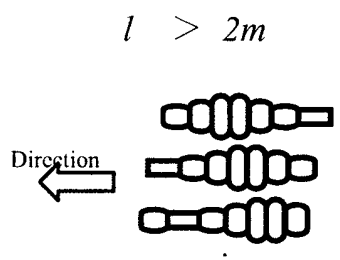




\section{2 理铪速度}

工業用内視鏡ロボットとしての目標速度は $5[\mathrm{~mm} / \mathrm{s}]$ である. 理論から速度を求め, 目標速度を满たすユニット数と動作を 検証した。

中間の動作を考えない場合の理論速度は，ユニットの膨張 収縮にかかる時問を $\tau_{D}(t), 1$ ユニットの収縮量を $r$ とし, 波の 伝播が 1 周するときに前進する距離を $d$ と置くと，

$$
d=r s l
$$

となり， 1 鳳期にかかる時間 $T$ は

$$
T=\frac{N \tau_{0}(t)}{n}
$$

となる。式(4)式(5)よりロボットの理論速度 $v$ は

$$
v=\frac{d}{T}=\frac{r n s l}{N \tau_{0}(t)}
$$

は波の伝播が一周するときに前進する距離を $d^{n}$, と置くと，

$$
d^{\prime}=r s\left(l-2 \sum_{i=1}^{m-1} i / m\right)
$$

となり， 1 楇期にかかる時問 $T$ ，は

$$
T^{\prime}=\frac{N \tau_{0}(t)}{m}
$$

となる. 式(7)式(8)よりロボットの理論速度 $v$ は

$$
v^{\prime}=\frac{d^{\prime}}{T^{\prime}}=\frac{m s\left(l-2 \sum_{i=1}^{m-1} i / m\right)}{N \tau_{0}(t)}
$$

となる。ここで, モータの回伝速度を $\omega$, ネジのピッチを $p$ とするとユニットの膨張収縮にかかる時間 $\tau_{0}(t)$ は

$$
\tau_{0}(t)=\frac{r}{p \omega}
$$

と表せ，式(6)式(9)に式(10)を代人すると

$$
\begin{gathered}
v=\frac{d}{T}=\frac{n s l p \omega}{N} \\
v^{\prime}=\frac{d^{\prime}}{T^{\prime}}=\frac{m s\left(l-2 \sum_{i=1}^{m-1} i / m\right) p \omega}{N}
\end{gathered}
$$

となる.速度の式から 1 ユニットの収縮量 $r$ を除くことができ るので, 収 縮量の值で速度は変化しないことがわかる。この ことより，モータの速度が変化しなければ，内径の多少異な る管でもほぼ|问等の速度が出せることがわかる。

式(9), 式(12)を元に月標速度 $5[\mathrm{~mm} / \mathrm{s}]$ を満たすユニット数を計 算したところ, 7 ユニットの時に日標速度を満たせることがわ かった．７ユニットの理論速度をまとめたグラフを図 6 に小 す.この際に $\tau_{0}(t)$ は $P=2, \omega=2.7[\mathrm{rps}]$ から求められるが, 製作 したユニットの伸縮速度を計測した絬果, 若干伸縮速度が遅 くなることがわかったので，計測值を使って $\tau_{0}(t)$ を算出した。 この図より 7 ユニットを用いた際に, 目標速度を達成可能な パターンが伱在するとわかる.

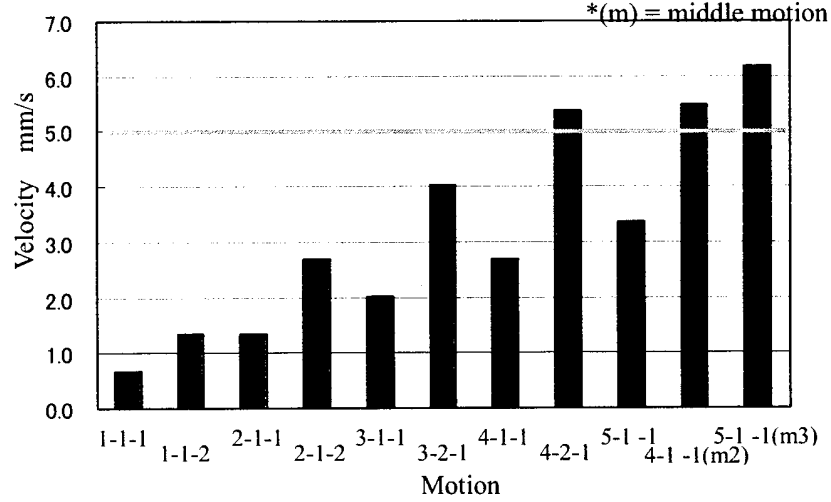

Fig. 6 Theoretical velocity

\section{3 走行实験}

式(9), 式(12)を確かめるために 7 ユニットから成るロボット を使用し，モーション4-2-1と 5-1-1(m)で, 内径 27 [mm]のア クリル管内と $25 \mathrm{~A}$ アルミ管内を走行させる実験を行った。ア クリル管内の走行実験ではロボットの先頭から各ユニットの 中心部に計七つの標点を付け，動画解析ソフト(NAC, movias) を用いてそれぞれのユニットの動作解析を行った。

さらに，理論と実際の動きにどの様な違いが動作のどの段 階で出るのかを検証するために，理論のとおりに動いたとき の各ユニットの位置を求めた。速度の比較を Table 2 に, 実速 度の此較を図 7 , 図 8 亦す。

Table 2 experimental results

\begin{tabular}{|l|c|c|c|}
\cline { 2 - 4 } \multicolumn{1}{c|}{} & $\begin{array}{c}\text { Theoretical } \\
\text { velocity }\end{array}$ & $\begin{array}{c}\text { Acrylic } \\
\text { pipe }\end{array}$ & $\begin{array}{c}\text { Aluminum } \\
\text { pipe }\end{array}$ \\
\hline $4-2-1[\mathrm{~mm} / \mathrm{s}]$ & 5.4 & 4.1 & 3.8 \\
\hline $5-1-1(\mathrm{~m})[\mathrm{mm} / \mathrm{s}]$ & 6.2 & 5.2 & 4.9 \\
\hline
\end{tabular}

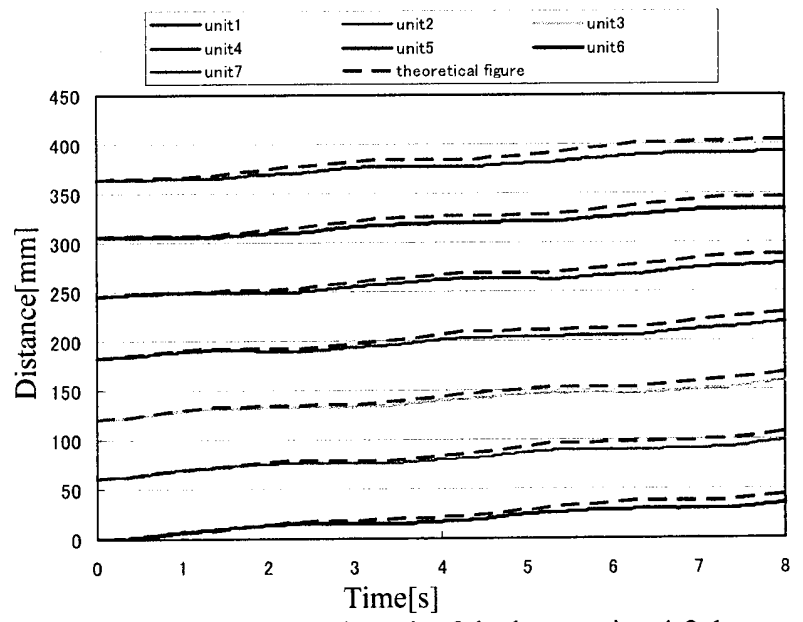

Fig. 7 Experimental result of the locomotion 4-2-1 


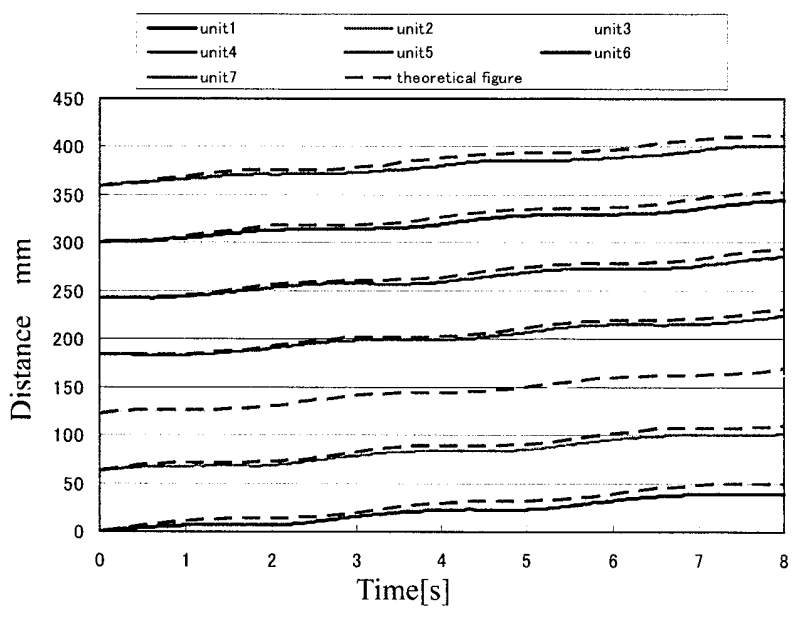

Fig. 8 Experimental result of the locomotion 5-1-1(m3)

図 7, 図 8 からわかるように波が頭部から順に尾部一と伝播 している事が確認でき, 本ロボットが理論と闹じ様に蝡動運 動を行いながら管内を前進していることが確認できた。また， 理論速度を実現することはできなかったが，5-1-1(m)の動作で 月標速度の $5[\mathrm{~mm} / \mathrm{s}]$ をほぼ実現することが出来た。

図 7, 図 8 からいくつかのユニットの動作時にグラフの傾き が理諭と若干異なってしまっていることがわかる。これは, 理論ではユニット単体で動かした時のデータを使っているが， 実際の動作では前後のユニットからノを受けており，そのノ がモータへの負荷となって回転速度が低トしてしまったこと が原因である。さらに，これらの理諭值との鿁差は，波の伝 播と监に他のニニットに伝わり，蓄積されていくことがわか る.

\section{5. ロボットの推進力実験}

曲管を通過する際には画管の走行時と比べて多くの推進ノ が必要となる。既任の工栄用内视鏡を丁:動でエルボ管(曲管) に㧇人する際に必要とする推進的 $9[\mathrm{~N}]$ である.この $9[\mathrm{~N}]$ を月標とし，本ロボットの推進ノを測定した．実験装置を Fig. 12 にボ寸. 抑し込みはモーション 5-1-1(m3)で 3.52 [N]であっ た. ユニット単体の伸偯力は $44.2[\mathrm{~N}]$ であることを苊えると ユニットのノを推進ノとして十分発捙することが出米ていな

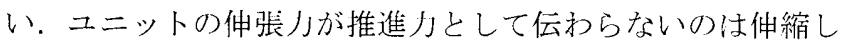
ているユニットが推進ノを十分に支えるだけの摩擦ノを州せ ていないためである. 収縮して壁面に接地しているニニット が，他のユニットから受けるノに負けて滑り出してしまう。 そこで，エルボ管通過時には推進ノを強化するモーションに 切り替えることで $9[\mathrm{~N}]$ の推進力を出せないかと考えた。動作 時に収縮しているユニットの数を增やせばロボットの摩擦ノ が㙼し，推進ノを增加させることができる。

モーション 5-1-1(m3)で動作時に常に伸縮しているユニット数 は1である.これをモーション1-1-1に変更すると常に伸縮し ているユニット数は 5 となる。このことにより, 摩擦ノを確 保して推進ノを出せる。

動作を変えて押し込み」を測定した絬果を Fig. 12 に六す。計 測絬果よりモーション 1-1-1 では日標の 9[N]の押し込みノを 達成できた. 今後, ロボット先端に屈曲機構を付けて実際に エルボ管通過を日指す。

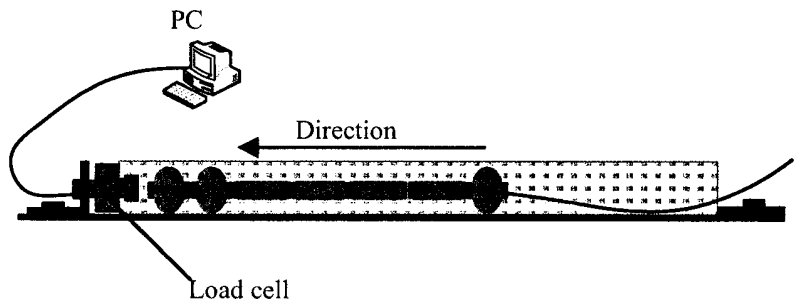

Fig. 6 experimental equipment

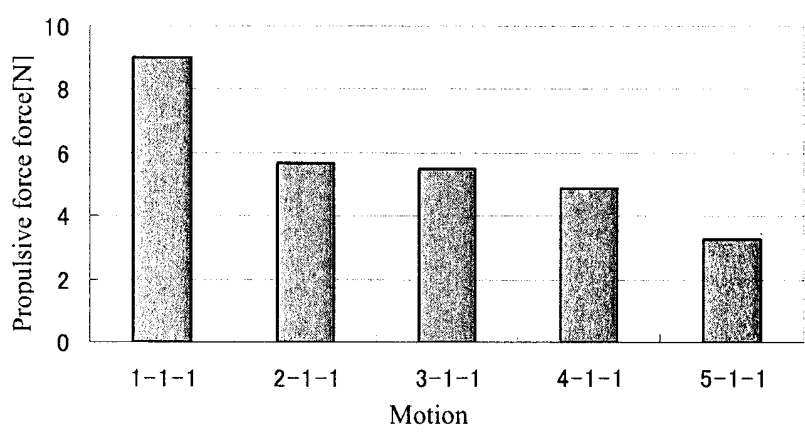

Fig. 13 The relationship between propulsive force

and motion patterns

\section{6. 結言}

本研究ではミミズの螦動運動に着月し, 絒アルミ管内で走 行可能なロボットの開発を行った。また, 動作を検討するこ とで日標速度 $5[\mathrm{~mm} / \mathrm{s}]$ を満たし，推進ノ9[N]を実現した。 今後の検討課題としてはエルボ管を通逦できる屈曲機構の搭 載・污れのある管内での走行・ $15 \mathrm{~A}($ 内径 $17[\mathrm{~mm}])$ で走行可能 な実機の作製・防水性の検討などがある.

\section{文 献}

[1]（2）尼陽雅司，畑崎計成，做崎和也，田所諭， "Development of an Active Scopecamera Driven by Ciliary Vibration Mechanism"ROBOTICS Symposia 2007.3.15.16

[2] Akira KUWADA, Kodai TSUJINO, Koichi SUZUMORI, Takefumi KAWADA (Okayama University) “Intelligent Actuators Realizing Snake-like Robot for Pipe Inspection", Proc. IEEE 2006 International Symposium on Micro-Nano Mechatronics and Human Science, 2006-11

[3] 三田純義, 朝比奈奎一，黑田孝龺，山口健二，“機械設 垶法”コロナ社, pp. $75-79$. 